\title{
Values in Science beyond Underdetermination and Inductive Risk
}

\author{
Matthew J. Brown \\ Center for Values in Medicine, Science, and Technology \\ The University of Texas at Dallas \\ mattbrown@utdallas.edu
}

July 12,2012

\begin{abstract}
The thesis that the practice and evaluation of science requires social valuejudgment, that good science is not value-free or value-neutral but value-laden, has been gaining acceptance among philosophers of science. The main proponents of the value-ladenness of science rely on either arguments from the underdetermination of theory by evidence or arguments from inductive risk. Both arguments share the premise that we should only consider values once the evidence runs out, or where it leaves uncertainty; they adopt a criterion of lexical priority of evidence over values. The motivation behind lexical priority is to avoid reaching conclusions on the basis of wishful thinking rather than good evidence. The problem of wishful thinking is indeed real-it would be an egregious error to adopt beliefs about the world because they comport with how one would prefer the world to be. I will argue, however, that giving lexical priority to evidential considerations over values is a mistake, and unnecessary for adequately avoiding the problem of wishful thinking. Values have a deeper role to play in science than proponents of the underdetermination and inductive risk arguments have suggested.
\end{abstract}

\section{Introduction}

This paper is part of the larger project of trying to understand the structure of values in science, i.e., the role of values in the logic of scientific practice. This is 
distinct from the project of strategic arguments that try to establish that science is value-laden while assuming premises of the defenders of the value-free ideal of science. It is becoming increasingly hard to deny that values play a role in scientific practice - specifically non-epistemic, non-cognitive, or contextual values, e.g., moral, political, and aesthetic values (I will use the term "social values" to refer to such values in general). What is less clear is what parts of scientific practice require values or value-judgments. This is not primarily a historical or sociological question, though historical and sociological data is frequently brought to bear. Ultimately it is a normative question about the role that value-judgments ought to play in science; it is a question about the proper ideal of scientific practice. As such, we must consider both ethical questions about how the responsible conduct of science requires valuejudgment and epistemological questions about how the objectivity and reliability of science is to be preserved.

There are a number of phases of inquiry where values might play a role: (1) in determing the value of science itself and (2) the research agenda to be pursued, (3) in framing the problem under investigation and (4) the methods of data collection and characterization, (5) in choosing the hypothesis, explanation, or solution to propose, (6) in the testing or certification of a proposed solution, and (7) in choices about application and dissemination of results. Various accounts have allowed values in some stages while excluding it in others, or have argued for specific limits on the role for values at each stage. In this paper, I will focus on the testing phase, where theories are compared with evidence and certified (or not) as knowledge, as this is the most central arena for discussion value-free vs. value-laden science. Traditionally, philosophers of science have accepted a role for values in practice because it could be marginalized into the "context of discovery," while the "context of justification" could be treated as epistemically pure. Once we turn from the logical context of justification to the actual context of certification ${ }^{1}$ in practice, the testing of hypotheses within concrete inquiries conducted by particular scientists, we can no longer ignore the role of value-judgments.

There are two main arguments in the literature for this claim: the error argument from inductive risk and the gap argument from the underdetermination of theory by evidence. While both of these arguments have been historically very important and have successfully established important roles for values in science, they share a flawed

\footnotetext{
${ }^{1}$ I use "context of certification" following Kitcher (2011), as referring to actual practices of acceptance. While I won't emphasize it in this paper, I also follow Kitcher in thinking that certification is a social practice that results in accepting a result as part of public knowledge (as opposed to merely individual belief).
} 
premise, the lexical priority of evidence over values. ${ }^{2}$ While this premise serves an important aim, that of avoiding the problem of wishful thinking, I will argue that there are several problems with this premise. We should seek an alternative ideal for science that provides a role for values at a more fundamental level and broader scope, but nevertheless preserves an important feature of science: the ability to surprise us with new information beyond or contrary to what we already hope or believe to be true.

\section{Underdetermination: The Gap Argument}

Underdetermination arguments for the value-ladenness of science extend Duhem's and Quine's thoughts about testing and certification. The starting point for this argument may be the so-called Duhem-Quine Thesis (or Duhem-Neurath-Quine Thesis (Rutte, 1991, p. 87)) that no hypothesis can be tested in isolation because of the need for auxiliary assumptions in order for theories to generate testable hypotheses. This is generally taken to imply that no theory can be definitively falsified by evidence, as the choice between rejecting the theory, altering the background assumptions, or even (though more controversially) rejecting the new evidence itself as faulty is underdetermined by each new item of evidence - call this "holist underdetermination" (Stanford, 2009).

Another form of underdetermination - "contrastive underdetermination" (ibid.) depends on the choice between identically confirmed rival hypotheses. As all of the evidence available equally supports either hypothesis in such cases, that choice is underdetermined by the evidence. If the evidence we're talking about is just all the evidence we have available to us at present, then we have transient underdetermination, which might be relatively temporary or might be a recurrent problem. If instead the choice is underdetermined by all possible evidence, we have permanent underdetermination and the competing theories or hypotheses are empirically equivalent. The global underdetermination thesis holds that permanent underdetermination is ubiquitous in science, applying to all theories and hypotheses. ${ }^{3}$

The many forms of underdetermination argument have in common the idea that some form of gap exists between theory and observation. Feminists, pragmatists,

\footnotetext{
${ }^{2}$ Strictly speaking, both arguments can be taken as strategic arguments, compatible with any positive approach to the role of values in scientific inquiry. For the purposes of this paper, I will instead take the arguments as attempts to articulate a positive ideal. The gap and error arguments are perfectly serviceable as strategic arguments.

${ }^{3}$ For discussion of forms of underdetermination, see Kitcher (2001); Magnus (2003); Stanford (2009); Intemann (2005); Biddle (2011).
} 
and others have sought to fill that gap with social values, or to argue that doing so does not violate rational prescriptions on scientific inference. Call this the gap argument for value-laden science (Intemann, 2005; Elliott, 2011). Kitcher (2001) has argued that permanent or global underdetermination is needed to defeat the value-free ideal of science, and these forms of underdetermination are much more controversial. Transient underdetermination, on the other hand, is "familiar and unthreatening," even "mundane" (Kitcher, 2001, p. 30-1)

Kitcher is wrong on this point; transient underdetermination is sufficient to establish the value-ladenness of scientific practice (Biddle, 2011). What matters are decisions made in practice by actual scientists, and at least in many areas of cutting edge and policy-relevant science, transient underdetermination is pervasive. Perhaps it is the case that in the long run of science (in an imagined Peircean "end of inquiry") all value-judgments would wash out. But as the cliché goes, in the long run we're all dead; for the purposes of this discussion, what we're concerned with is decisions made now, in the actual course of scientific practices, where the decision to accept or reject a hypothesis has pressing consequences. In such cases, we cannot wait for the end of inquiry for scientists to accept or reject a hypothesis, we cannot depend on anyone else to do it, and we must contend with uncertainty and underdetermination. Actual scientific practice supports this - scientists find themselves in the business of accepting and rejecting hypotheses in such conditions.

So what is the role for social values under conditions of transient underdetermination? Once the existing evidence is in, a gap remains in definitively determining how it bears on the hypothesis (holist case) or which competing hypothesis to accept (contrastive case). In this case, it can be legitimate to fill the gap with social values. For example, among the competing hypotheses still compatible with all the evidence, one might accept the one whose acceptance is likely to do the most good or the least harm. E.g., in social science work involving gender or race, this might be the hypothesis compatible with egalitarianism.

A common response is that despite the existence of the gap, we should ensure that no social values enter into decisions about how to make the underdetermined choice (e.g., whether or not to accept a hypothesis). Instead, we might fill the gap with more complex inferential criteria (Norton, 2008) or with so-called "epistemic" or "cognitive" values (Kuhn, 1977; Laudan, 1984). Proponents of the gap argument have argued that this at best pushes the question back one level, as choices of epistemic criteria or cognitive values (Longino, 2002, p. 185), and application of cognitive values itself may not be entirely determinate (Kuhn, 1977). Ensuring that no values actually enter into decisions to accept or reject hypotheses under conditions of transient underdetermination may turn out to be impossible (Biddle, 2011). 
Another attempt to avoid a role for social value-judgments - withholding judgment until transient underdetermination can be overcome or resolved by application of cognitive factors along - is unreasonable or irresponsible in many cases, e.g. where urgent action requires commitment to one or another option (ibid.). ${ }^{4}$

What distinguishes legitimate from illegitimate uses of values to fill the gap is a matter of controversy, sometimes left unspecified. With some exceptions, ${ }^{5}$ underdeterminationists insist that values only come into play in filling the gap (e.g., Longino, 1990, p. 52, 2002, p. 127; Kourany, 2003).

\section{Inductive Risk: The Error Argument}

While underdeterminationist arguments for values in science are probably more well known, and may have a history going back a paper of Neurath's from 1913 (Howard, 2006), the inductive risk argument for values in science is older still, going back to William James' (1896) article "The Will to Believe." 6 Heather Douglas has revived Rudner's (1953) and Hempel's (1965) version of the argument for the value-ladenness of science. In simplified form, the argument goes like this:

In accepting or rejecting hypotheses, scientists can never have complete certainty that they are making the right choice - uncertainty is endemic to ampliative inference. So, inquirers must decide whether there is enough evidence to accept or reject the hypothesis. What counts as enough should be determined by how important the question is, i.e., the seriousness of making a mistake. That importance or seriousness is generally (in part) an ethical question, dependent on the ethical evaluation of the consequences of error. Call this argument for the use of value-judgments in science from the existence of inductive risk the error argument (Elliott, 2011).

According to the error argument, the main role for values in certification of scientific hypotheses has to do with how much uncertainty to accept, or how strict to make your standards for acceptance. In statistical contexts, we can think of this as the trade-off between type $I$ and type $I I$ error. Once we have a fixed sample size (and assuming we have no control over the effect size), the only way we can decrease the probability that we wrongly reject the null hypothesis is to increase the probability

\footnotetext{
${ }^{4}$ Proponents of the inductive risk argument make a similar point.

${ }^{5}$ These exceptions either use a somewhat different sort of appeal to underdetermination than the gap argument, or they use the gap argument as a strategic argument. One example is the extension of the Quinean web of belief to include value-judgments (Nelson, 1990), discussed in more detail below.

${ }^{6}$ This connection is due to P.D. Magnus (2012), who refers to the inductive risk argument as the "James-Rudner-Douglas or JRD thesis" for reasons that will become immediately apparent.
} 
that we wrongly accept the null hypothesis (or, perhaps more carefully, that we fail to reject the null hypothesis when it is in fact false), and vice versa. Suppose we are looking for a causal link between a certain chemical compound and liver cancers in rats, ${ }^{7}$ and you take $H_{0}$ to be no link whatsoever. If you want to be absolutely sure that you don't say that the chemical is safe when it in fact is not (because you value safety, precaution, welfare of potential third parties), you should decrease your rate of type II errors, and thus increase your statistical significance factor and your rate of type I errors. If you want to avoid "crying wolf" and asserting a link where none exists (because you value economic benefits that come with avoiding overregulation), you should do the reverse.

Douglas emphasizes at length that values (neither social nor cognitive values) should not be taken as reasons for accepting or rejecting a hypothesis, reasons on a par with or having the same sort of role as evidence in testing. ${ }^{8}$ This is an impermissible direct role for values. In their permissible indirect role, values help determine the rules of scientific method, e.g., decisions about how many false positives or false negatives to accept. Values are not reasons guiding belief or acceptance; they instead guide decisions about how to manage uncertainty. ${ }^{9}$

Rudner (1953) anticipated the objection that scientists should not be in the business of accepting or rejecting hypothesis, but rather just indicating their probability (and thus not having to make the decision described above). This response wrongly assumes that inductive risk only occurs at the final step of certification; in reality, this gambit only pushes the inductive risk back a step to the determination of probabilities. Furthermore, the pragmatic signal that accompanies a refusal to assent or deny a claim in practical or policy circumstances may be that the claim is far more questionable that the probabilities support. Simply ignoring the consequences of error - by refusing to accept or reject, by relying only on cognitive values, or by choosing purely conventional levels for error - may be irresponsible, as scientists like anyone else have the moral responsibility to consider the foreseeable consequences of their action.

\footnotetext{
${ }^{7}$ Douglas (2000) considers the actual research on this link with dioxin.

${ }^{8}$ Strictly speaking, this is an extension of the error argument, and not all who accept the argument (especially for strategic purposes) need accept this addition.

${ }^{9}$ In Toulmin's (1958) terms, values cannot work as grounds for claims, but they can work as backing for warrants.
} 


\section{A Shared Premise}

These two arguments against the value-free ideal of science share a common premise. The gap argument holds that values can play a role in the space fixed by the evidence; if the gap narrows (as it would with transient underdetermination), there are fewer ways in which values can play a role, and if the gap could ever be close, the conclusion would be value-free. (An exception are those views that add values into the radically holistic interpretation of Quine's web of belief, such that values, theories, and evidence are all equally revisable in the light of new evidence.) The inductive risk argument allows values to play a role in decisions about how to manage uncertainty — not directly by telling us which option to pick, but indirectly in determining how much uncertainty is acceptable.

Both arguments begin from a situation where the evidence is fixed and take values to play a role in the space that is left over. The reason that values must play a role is that uncertainty remains once the evidence is in. In a relatively weak version of this argument, social values fill in the space between evidence and theory because something has to, so it might as well be (and often is) social values. In more sophisticated versions, we must use social values to fill the gap because of our general moral obligation to consider the foreseeable consequences of our actions, including the action of accepting a hypothesis. The arguments of these two general forms all assume the lexical priority of evidence over values. The premise of lexical priority guarantees that even in value-laden science, values do not compete with evidence when the two conflict. This is often defended as an important guarantor of the objectivity or reliability of the science in question.

\section{$5 \quad$ Why Priority?}

Why do proponents of value-laden science tend to be attracted to such a strict priority of evidence over values? Perhaps some such restriction is required in order to guarantee the objectivity of science. In order for our science to be as objective as possible, maybe it has to be as value-free as possible (though this may not be very value-free at all). That is, we want as much as possible to base our science on the evidence because evidence lends objectivity and values detract from it. Even if this view of objectivity were right, however, it would be a problematic justification for opponents of the value-free ideal of science to adopt. With arguments like the gap and inductive risk arguments, they mean to argue that values and objectivity are not in conflict as such. It would thus create a serious tension in their view if one premise depended on such a conflict. If it is really objectivity that is at stake in adopting 
lexical priority, we need a more nuanced approach.

I think the central concern concern is that value judgments might "drive inquiry to a predetermined conclusion" (Anderson, 2004, p. 11), that inquirers might rig the game in favor of their preferred values. As Douglas (2009) puts it, "Values are not evidence; wishing does not make it so" (p. 87). In other words, a core value of science is its ability to surprise us, to force us to revise our thinking. Call the threat of values interfering with this process the problem of wishful thinking.

Lexical priority avoids this problem insofar as what we value (which involves the way we desire the world to be) is only a consideration after we take all of the evidence (which fixes the way the world is) into account. In Douglas's more nuanced approach, even once the evidence is in, social values (and even most cognitive values) are not allowed to be taken directly as reasons to believe anything; they only act as reasons for accepting a certain amount of evidence as "enough."

An alternative explanation may be that the adoption of lexical priority has rhetorical value. ${ }^{10}$ Suppose, along with the defenders of the value-free ideal, that there is such a thing as objective evidence which constrains belief. Even so, there is (at least transient) underdetermination, and a gap that must bridged by social values. Thus not only is the value-free ideal impossible to realize, it may lead to unreasonable and irresponsible avoidance of the role for values in filling the gap. Such an argument can undermine the value-free ideal and establish that there is a major role for values in science, and in the context of these goals, I freely admit that this can be a worthwhile strategy. But as we turn instead to the positive project of determining more precisely the role(s) of values in the logic of scientific practice, the premises of such an immanent critique are unfit ground for further development. We no longer need to take the premises of our opponents on board, and we may find that they lead us astray.

While following the basic contours of my argument so far, one might object to characterizing of evidence as "prior" to values. ${ }^{11}$ What the gap and inductive risk arguments purport to show is that there is always some uncertainty in scientific inference (perhaps, for even more basic reasons, in all ampliative inference), and so there will always be value-judgments to be made about when we have enough evidence, or which among equally supported hypotheses we wish to accept, etc. The pervasive need for such judgments means that value-freedom does not even make sense as a limiting case; both values and evidence play a role, and neither is prior to the other. This mistakes the sense of "priority" at work, however. Where priority matters is what happens when values and evidence conflict; in such circumstances,

\footnotetext{
${ }^{10}$ Note redacted for purposes of anonymous review.

${ }^{11}$ Note redacted for purposes of anonymous review.
} 
lexical priority means that evidence will always trump values. In Douglas's stronger version of lexical priority, values allow you to determined what level of evidence you need to accept a hypothesis $(p=0.05$ or $p=0.01$ or...), but they cannot give you a reason to reject the hypothesis, ${ }^{12}$ no matter what.

\section{Problems with Priority}

The versions of the gap and inductive risk arguments that presuppose the lexical priority of evidence make two related mistakes. First, they require a relatively uncritical stance towards the status of evidence within the context of certification. ${ }^{13}$ The lexical priority principle assumes that in testing, we ask: given the evidence, what should we make of our hypothesis? Frame this way, values only play a role at the margins of the process.

This is a mistake, since evidence can turn out to be bad in all sorts of ways: unreliable, unrepresentative, noisy, laden with unsuitable concepts and interpretations, or irrelevant for the question at hand; the experimental apparatus could even have a cord loose. More importantly, we may be totally unaware of why the evidence is bad; after all, it took a great deal of ingenuity on the part of Galileo to show why the tower experiment didn't refute Copernicus, and it took much longer to deal with the problem of the "missing" stellar parallax. While some epistemologists stick to an abstract conception of evidence according to which evidence is itself unquestionable, reflection on cases like this has lead many philosophers of science to recognize that we can be skeptical about particular pieces or sets of evidence based on its clash with hypotheses, theories, or background assumptions that we have other good reasons to hold on to. As critics of strict falsificationism and empiricism have shown, we already have reason to adopt a more egalitarian account of the process of testing and certification, independent of the question about the role of values. We might get off to a better start if we thought about how to fit values into this sort of picture of testing.

\footnotetext{
${ }^{12}$ It seems possible that we could use our extreme aversion to some hypothesis to raise the required level of certainty so high as to be at least practically unsatisfiable by human inquirers, and so in effect rule out the hypothesis on the basis of values alone while remaining in the indirect role. While it isn't clear how to do it, it seems to be that Douglas means to rule this sort of case out as well.

${ }^{13}$ As Douglas (2009) makes clear, she does not take the status of evidence as unproblematic as such. But any issues with the evidence are to be taken into account by prior consideration of values in selection of methods and characterization of data. It would seem that value judgments in the context of certification cannot be a reason to challenge the evidence itself. The following points are intended to show that this restriction is unreasonable.
} 
Second, the attitude about values that lexical priority takes reduces the idea of value judgment to merely expression of preferences rather than judgment properly so called - in effect, they deny that we can have good reasons for our value judgments. It is crucial to distinguish between values or valuing and value judgments or evaluations (Dewey, 1915, 1939; Welchman, 2002; Anderson, 2010). Valuing may be the mere expression of a preference, but value judgments are reflective decisions about values, and properly speaking must be made on the basis of reasons (and judgments can be better or worse because they are made on the basis of good and bad reasons). Value judgments may even be open to a certain sort of empirical test, because they hypothesize relationships between a state or course of action to prefer and pursue and the desirability or value of the consequences of pursuing and attaining them (Dewey, 1915; Anderson, 2010). Value judgments say something like "try it, you'll like it" - a testable hypothesis (Anderson, 2010). The evidence by which we test value judgments may include the emotional experiences that follow on adopting those values (Anderson, 2004).

If value judgments are judgments properly so called, adopted for good reasons, subject to certain sorts of tests, then it is unreasonable to treat them in the manner required by the lexical priority of evidence. Just as the good (partly empirical) reasons for adopting a theory, hypothesis, or background assumption can give us good reasons to reinterpret, reject, or maybe even ignore evidence apparently in conflict with them (under certain conditions), so too with a good value judgment. If evidence and values pull in opposite directions on the acceptance of a hypothesis, then we should not always be forced to follow the (putative) evidence.

\section{Avoiding Wishful Thinking without Priority}

If we reject the lexical priority assumption and adopt a more egalitarian model of testing, we need to adopt an alternative approach that can avoid the problem of wishful thinking.

(An alternative principle to lexical priority is the joint necessity of evidence and values, which requires joint satisfaction of epistemic criteria and social values. This is the approach taken by Kourany (2010). On such a view, neither evidence nor values takes priority, but this principle leaves open the question of what to do when evidence and values clash. One option is to remain dogmatic about both epistemic criteria and social values, and to regard any solution which flouts either as a failure, which appears to be Kourany's response.

Alternatively, we can adopt the rational revisability of evidence and values in addition to joint necessity and revisit and refine our evidence or values. On this 
principle, both the production of evidence and value formation are recognized as rational but fallible processes, open to revision. Such a view might include the radical version of Quinean holism which inserts values into the web of belief. The adoption of these two principles alone does not prevent wishful thinking, but adding some basic principles like minimal mutilation may overcome the problem. (cf. Kitcher, 2011)

Instead of Quinean holism, we might instead adopt a form of pragmatist functionalism about inquiry (Brown, 2012) which differentiates the functional roles of evidence, theory, and values in inquiry. This retains the idea that all three have to be coordinated and that each is revisable in the face of new experience, while introducing further structure into their interactions and According to such an account, not only must evidence, theory, and values fit together fit together in their functional roles, they must do so in a way that actually resolves the problem that spurred the inquiry.

\section{Conclusion}

The lexical priority of evidence over values is an undesirable commitment, and unnecessary for solving the problem it was intended to solve. The key to the problem of wishful thinking is that we not predetermine the conclusion of inquiry, that we leave ourself open to surprise. The real problem is not the insertion of values, but dogmatism about values (Anderson 2004). Rather than being the best way to avoid dogmatism, the lexical priority of evidence over values coheres best with a dogmatic picture of value judgments, and so encourages the illegitimate use of values. A better account is one where values and evidence are treated as mutually necessary, functionally differentiated, and rationally revisable components of certification. Such an account would allow that evidence may be rejected because of lack of fit with a favored hypothesis and compelling value-judgments, but only so long as one is still able to effectively solve the problem of inquiry.

\section{References}

Anderson, E. (2004). Uses of value judgments in science: A general argument, with lessons from a case study of feminist research on divorce. Hypatia 19(1), 1-24.

Anderson, E. (2010). Dewey's moral philosophy. In E. N. Zalta (Ed.), The Stanford Encyclopedia of Philosophy (Fall 2010 ed.). 
Biddle, J. (2011, October). Transient underdetermination, value freedom, and the epistemic purity of science. Unpublished manuscript.

Brown, M. J. (2012, Fall). John Dewey's Logic of Science. HOPOS: The Journal of the International Society for the History of Philosophy of Science 2(2).

Dewey, J. (1915). The logic of judgments of practice. In J. A. Boydston (Ed.), The Middle Works, 1899-1924, Volume 8. Carbondale: Southern Illinois University Press.

Dewey, J. (1939). Theory of Valuation. In J. A. Boydston (Ed.), The Later Works, 1925-1953, Volume 13. Carbondale: Southern Illinois University Press.

Douglas, H. (2000). Inductive risk and values in science. Philosophy of Science 67(4), $559-579$.

Douglas, H. (2009). Science, Policy, and the Value-Free Ideal. Pittsburgh: University of Pittsburgh Press.

Elliott, K. C. (2011). Is a little pollution good for you?: incorporating societal values in environmental research. Environmental ethics and science policy series. New York: Oxford University Press.

Hempel, C. G. (1965). Science and human values. In Aspects of Scientific Explanation and other Essays in the Philosophy of Science, pp. 81-96. New York: The Free Press.

Howard, D. (2006). Lost wanderers in the forest of knowledge: Some thoughts on the discovery-justification distinction. In J. Schickore and F. Steinle (Eds.), Revisiting Discovery and Justification: Historical and Philosophical Perspectives on the Context Distinction, pp. 3-22. Dordrecht: Springer.

Intemann, K. (2005). Feminism, underdetermination, and values in science. Philosophy of science 72(5), 1001-1012.

James, W. (1896). The will to believe. The New World 5, 327-347.

Kitcher, P. (2001). Science, Truth, and Democracy. Oxford University Press.

Kitcher, P. (2011). Science in a democratic society. Amherst, N.Y.: Prometheus Books. 
Kourany, J. A. (2003). A philosophy of science for the twenty-first century. Philosophy of science $70(1), 1-14$.

Kourany, J. A. (2010). Philosophy of science after feminism. Oxford Univ Pr.

Kuhn, T. S. (1977). Objectivity, Value Judgment, and Theory Choice, pp. 320-39. Chicago: University of Chicago Press.

Laudan, L. (1984). Science and values: the aims of science and their role in scientific debate. Berkeley: University of California Press.

Longino, H. E. (1990). Science as social knowledge: values and objectivity in scientific inquiry. Princeton, N.J.: Princeton University Press.

Longino, H. E. (2002). The fate of knowledge. Princeton University Press.

Magnus, P. (2003). Underdetermination and the Claims of Science. Ph. D. thesis, University of California, San Diego.

Magnus, P. (2012). What scientists know is not a function of what scientists know. In PSA 2012.

Nelson, L. H. (1990). Who knows: from Quine to a feminist empiricism. Philadelphia: Temple University Press.

Norton, J. (2008). Must evidence underdetermine theory. The challenge of the social and the pressure of practice: Science and values revisited, 17-44.

Rudner, R. (1953). The scientist qua scientist makes value judgments. Philosophy of Science 20(1), 1-6.

Rutte, H. (1991). The Philosopher Otto Neurath. In T. E. Uebel (Ed.), Rediscovering the Forgotten Vienna Circle: Austrian Studies on Otto Neurath and the Vienna Circle, Kluwer Academic Publishers, Dordrecht, pp. 81-94. Kluwer Academic Publishers.

Stanford, K. (2009). Underdetermination of scientific theory. In E. N. Zalta (Ed.), The Stanford Encyclopedia of Philosophy (Winter 2009 ed.).

Toulmin, S. (1958). The Uses of Argument. Cambridge, U.K.: Cambridge University Press. 
Welchman, J. (2002). Logic and judgments of practice. In F. T. Burke, D. M. Hester, and R. B. Talisse (Eds.), Dewey's logical theory: new studies and interpretations. Vanderbilt Univ Press. 